\title{
Penicillin Production by Lysine Auxotrophs of Penicillium chrysogenum
}

\author{
By CHRISTINE Y. O'SULLIVAN* AND S. J. PIRT \\ Department of Microbiology, Queen Elizabeth College, \\ Campden Hill Road, London, W.8
}

(Received I8 August 1972; revised 30 November 1972)

\begin{abstract}
SUMMARY
The possibility of increasing the penicillin production of Penicillium chrysogenum by feeding lysine at low concentrations to lysine auxotrophs in which the lysine pathways are blocked after $\alpha$-aminoadipate has been investigated. Three such auxotrophs, strains $\mathrm{H}$, I3a and 45, were isolated after ultraviolet light treatment and characterized. Only one of these mutants (strain $\mathrm{H}$ ) could be induced to produce penicillin at a rate comparable to that of the parent strain; the others produced much smaller amounts. Chemostat continuous-flow culture of the parent strain and mutant strain $\mathrm{H}$ on increasing concentrations of lysine was undertaken. Microbiological assay of the lysine in the chemostat showed that it was completely utilized by both the parent strain and strain $\mathrm{H}$, even when fed at several times the amount required for growth. In the parent strain, the $q_{\text {pen }}$ slowly fell from a level of $2.94 \mathrm{u} / \mathrm{mg}$ dry biomass $/ \mathrm{h}$ at zero lysine feed concentrations to $0.45 \mathrm{u} / \mathrm{mg}$ dry biomass/h with lysine amounts up to $400 \mathrm{mg} / \mathrm{l}$ in the feed medium. When the mutant strain was grown under similar conditions, penicillin production was stimulated as lysine feed concentrations increased until at $180 \%$ excess over that required for growth, a $q_{\text {pen }}$ of $2.64 \mathrm{u} / \mathrm{mg}$ dry biomass $/ \mathrm{h}$ was reached, after which the $q_{\text {pen }}$ fell at a rate similar to that of the parent strain. At zero growth rate, $\alpha$-aminoadipic acid stimulated penicillin production, more so when fed continuously to the cultures than when it was added in a single dose. Thus it was found that when lysine was growth-limiting for the auxotroph, and consequently present at minimal concentrations in the mould, penicillin synthesis was inhibited rather than stimulated.
\end{abstract}

\section{INTRODUCTION}

The metabolic basis of the penicillin fermentation, like that of any other antibiotic production, is highly speculative and little understood. Hitherto development of productive strains of Penicillium for penicillin production can be attributed to random mutation which results in some modification of the regulation of metabolism that leads to an increased flow of metabolites into the pathway to penicillin. Once the metabolic pathway and its regulation are known it should be possible to modify the regulation at will, rather than at random. An approach of this type to the penicillin fermentation is described here.

The pathway leading to penicillin formation has not been completely elucidated although it is believed to be connected to the lysine biosynthetic pathway. Demain (1966) suggested that lysine and penicillin could be considered as end products of a branched pathway and that the inhibition of penicillin synthesis by lysine (Demain, 1957) was most likely caused by feedback inhibition/repression. Maragoudakis, Holmes \& Strassman (1967) and Tucci (I969) have shown that in yeast, lysine inhibits the first enzyme of the lysine biosynthetic

\footnotetext{
* Present address: Institute of Microbiology, Swiss Federal Institute of Technology, 8006 Zürich, Switzerland.
} 
pathway, homocitrate synthase, both in vitro and in vivo. Fig. I is a summary of the present state of knowledge regarding the lysine and penicillin biosynthetic pathways.

Wright \& Calam (I968) have compared penicillin production in batch and chemostat cultures and have shown that in batch cultures penicillin production is in a transient state where $q_{\text {pen }}$ rises to a maximum which is about three times the steady-state value achieved in a chemostat. It was postulated (Pirt, 1969) that if a lysine auxotroph of Penicillium chrysogenum, blocked after $\alpha$-aminoadipate, was fed lysine at such a low level that the feedback control would be overcome, the full potential of penicillin production would be realized. This postulate has been tested in the work reported here.

\section{METHODS}

Organism. Penicillium chrysogenum strain wIS $54-\mathrm{I} 255$ was supplied by Dr K. D. MacDonald (Microbiological Research Establishment, Porton, Salisbury, Wiltshire).

Media. The organism was maintained on agar slopes of the sporulation medium of Moyer \& Coghill (1946). Inocula were obtained by suspending spores from the slopes of 4-day-old cultures in $0.05 \%$ Manoxol OT. A final concentration of $\mathrm{I} \times 10^{7}$ spores $/ \mathrm{ml}$ was used in each experiment.

For batch experiments, the penicillin production medium of Jarvis \& Johnson (1947), JJI, was used. Phenylethylamine acetate $(\mathrm{I} \cdot 0 \mathrm{~g} / \mathrm{l})$ was used as the penicillin side-chain precursor.

For continuous-culture experiments, the medium (MI) of Pirt \& Callow (I960) was used with phenylethylamine acetate $(\mathrm{I} \cdot \mathrm{O} \mathrm{g} / \mathrm{l})$ as precursor. The glucose concentration was $8 \mathrm{~g} / \mathrm{l}$. Where stated, L-lysine monohydrochloride was added.

Growth. Batch experiments were carried out in $250 \mathrm{ml}$ shake flasks with orbital shaking (200 rev. $/ \mathrm{min}$ ) at $25^{\circ} \mathrm{C}$.

The chemostat continuous-culture experiments were done in the $\mathrm{CeCa}$ (Controlled Environment Culture Apparatus, A. Gallenkamp and Co. Ltd, London, E.C. 2). The culture volume was $5 \mathrm{l}$. Air was sparged in at $500 \mathrm{ml} / \mathrm{min}$, and aeration was achieved by vortex stirring with an impeller speed of $\mathrm{I} 200 \mathrm{rev} . / \mathrm{min}$. The medium (MI) was supplied to the vessel in two parts; (i) glucose and (ii) all other constituents. The dilution rate was kept constant for each experiment at $0.05 \mathrm{~h}^{-1}$ (doubling time $\mathrm{I} 4 \mathrm{~h}$ ). Temperature was controlled at $25^{\circ} \mathrm{C}$ and a $\mathrm{pH}$ value of 7.0 maintained by the automatic addition of $2 \mathrm{~N}-\mathrm{NaOH}$. Foaming was controlled by the automatic addition of polypropylene glycol (P 2000, Dow Chemicals Co. (U.K.) Ltd, London, W.I) at a fixed rate of $\mathrm{I} \mathrm{ml} / 24 \mathrm{~h}$.

Simulated second-stage chemostat studies. Samples $(25 \mathrm{ml})$ were taken from the chemostat during a steady state and placed in $250 \mathrm{ml}$ shake flasks. Glucose $(20 \% \mathrm{w} / \mathrm{v}), 3 \mathrm{mg}$ DL- $\alpha$-aminoadipate $/ \mathrm{ml}$ and $\mathrm{I} .5 \mathrm{mg} \mathrm{L}$-lysine $/ \mathrm{ml}$ were fed separately into these samples via diffusion capsules of orifice diam. $4.0 \mathrm{~mm}$ (Pirt, I97I ; manufactured by L. H. Engineering, Bells Hill, Stoke Poges, Buckinghamshire) and equivalent amounts were added directly to control flasks. These concentrations were found from preliminary experiments to allow a very slow linear growth of the organism. The flasks were shaken for $24 \mathrm{~h}$ on a rotary shaker (200 rev./min) at $25{ }^{\circ} \mathrm{C}$.

In the calculation of the $q_{\text {pen }}$ it was necessary to allow for any increase or decrease of biomass which occurred during the experiment. It was assumed that the $q_{\text {pen }}$ was unaffected by the growth rate (experimental evidence for this was given by Pirt \& Righelato, 1967); the $q_{\mathrm{pen}}$ can then be calculated from the equation:

$$
p=p_{0}+q_{\mathrm{pen}} \int_{0}^{t} x \mathrm{~d} t
$$


where $p_{0}=$ initial penicillin concentration, $t=$ time and $x=$ biomass concentration. When glucose was added to the flask in one dose (i.e. 'directly') growth was practically exponential. Hence substituting in (I) $x=x_{0} \mathrm{e}^{\mu t}$ where $\mu=$ specific growth rate $\left(\mathrm{h}^{-1}\right)$ we have

$$
q_{\mathrm{pen}}=\mu\left(p-p_{0}\right) / x_{0}\left(\mathrm{e}^{\mu t}-\mathrm{I}\right)
$$

When glucose was fed in by diffusion capsule the biomass increased at a linear rate $(k$, $\mathrm{mg} \mathrm{ml}^{-1} \mathrm{~h}^{-1}$ ) so that $x=x_{0}+k t$, where, if the growth yield is $Y \mathrm{~g}$ biomass/g glucose and $f$ is the feed rate of glucose in $g(\mathrm{ml} \mathrm{h})^{-1}, k=f Y$. Then we have:

$$
q_{\text {pen }}=\left(p-p_{0}\right) /\left(x_{0}+k t / 2\right) t \text {. }
$$

In the absence of added energy source, the mycelium decreased in weight at an approximately linear rate, so that $k$ was then negative.

Isolation of lysine auxotrophs. Two mutagenic agents, ultraviolet light (u.v.) and $N$-methyl$N^{\prime}$-nitro- $N$-nitrosoguanidine (NTG) were used prior to selection for lysine auxotrophs.

Ultraviolet light. Spores of Penicillium chrysogenum strain wIS 54-I255 were irradiated with a Hanovia UV lamp at a height of $30 \mathrm{~cm}$ for $3 \mathrm{~min}$. This time had been found to give a spore survival of $\mathrm{I} \%$. The treated spores were diluted and plated on to minimal medium (MM I, Pontecorvo et al. I 953) $+0.02 \%$ lysine $+0.1 \%$ sodium deoxycholate.

$N$-methy $/$ - $N^{\prime}$-nitro- $N$-nitrosoguanidine. The method of Adelberg, Mendel \& Chen (1965) as adapted by Clutterbuck \& Sinha (I966) was used. The recommended survival of $25 \%$ was achieved after treatment with $0.5 \mathrm{mg} / \mathrm{ml}$ (final concentration) NTG for $4.5 \mathrm{~min}$. The treated spores were washed twice and diluted before plating on to $\mathrm{MM} \mathrm{I}+0.02 \%$ lysine + $0.1 \%$ sodium deoxycholate.

Nutritional characterization of mutants. A final spore suspension of $\mathrm{I} \times 1 \mathrm{I}^{7} / \mathrm{ml}$ was added to molten MM I at $48{ }^{\circ} \mathrm{C}$ and plates were poured and allowed to set. Crystals of $\alpha$-ketoadipic acid, $x$-aminoadipic acid, saccharopine and lysine were stabbed into each plate. These were incubated at $25^{\circ} \mathrm{C}$ for 2 days after which presence and absence of growth zones were looked for.

Extraction and assay of enzymes. Cell-free preparations of Penicillium chrysogenum were obtained by treating the samples in a French pressure-cell press (American Instruments Co., Silver Spring, Maryland, U.S.A.) at a pressure of $2000 \mathrm{lb} / \mathrm{in}^{2}$. The disrupted mass was centrifuged at $35000 \mathrm{~g}$ for $30 \mathrm{~min}$. All operations were carried out at about $5{ }^{\circ} \mathrm{C}$. The supernatant fraction was used as the cell-free preparation. Three enzymes were assayed: $\alpha$-aminoadipic reductase by the method of Sagisaka \& Shimura (I959), saccharopine reductase by the method of Jones \& Broquist (1966), and saccharopine dehydrogenase by the method of Fjellstedt \& Ogur (1970).

Chromatography. Two-dimensional thin-layer chromatography using silica gel plates was carried out on the cell-free extract. The solvent systems used were: first dimension, butanol : acetone : ammonium hydroxide : water (I0:10:5:2, by vol.); second dimension, isopropanol: formic acid : water (20:I:5, by vol.).

The amino-acid spots were detected by spraying with $0.2 \%$ ninhydrin in absolute ethanol, followed by heating at $60{ }^{\circ} \mathrm{C}$ for $10 \mathrm{~min}$.

Analyses. To determine dry biomass, samples were passed through sintered glass crucibles (porosity $\times 2$ ), washed twice with distilled water and dried to a constant weight at $105{ }^{\circ} \mathrm{C}$. Glucose was estimated by the glucose oxidase method of Hugget \& Nixon (I957). Protein was estimated by the method of Lowry, Rosebrough, Farr \& Randall (I95I). Lysine was assayed microbiologically according to the method given in the Difco Manual (Difco 
Table I. Auxanography of lysine mutants of Penicillium chrysogenum

\begin{tabular}{|c|c|c|c|c|c|c|}
\hline \multirow[b]{2}{*}{ Strain } & \multirow[b]{2}{*}{$\begin{array}{c}\text { Mutagenic } \\
\text { treatment }\end{array}$} & \multirow[b]{2}{*}{ MM I } & \multicolumn{4}{|c|}{ Growth response } \\
\hline & & & $\begin{array}{l}\text { MM I }+\alpha \text {-keto- } \\
\text { adipate }\end{array}$ & $\begin{array}{l}\text { MM I }+\alpha \text {-amino- } \\
\text { adipate }\end{array}$ & $\begin{array}{l}\mathrm{MM}_{\mathrm{I}}+\text { saccha- } \\
\text { ropine }\end{array}$ & MM I + lysine \\
\hline $\mathrm{H}$ & u.v. & - & - & - & - & + \\
\hline $13 a$ & u.v. & - & - & - & - & + \\
\hline 45 & u.v. & - & - & - & - & + \\
\hline 27 & u.v. & - & - & + & - & + \\
\hline 25 & NTG & - & - & + & - & + \\
\hline
\end{tabular}

Table 2. Growth characteristics of Penicillium chrysogenum strains WIS 54-I255, $\mathrm{H}, \mathrm{I} 3 \mathrm{a}$ and 45 when grown on $\mathrm{JJ}_{\mathrm{I}}+$ glucose $(30 \mathrm{~g} / \mathrm{l})+$ lysine $(300 \mathrm{mg} / \mathrm{l})$

\begin{tabular}{|c|c|c|c|c|c|}
\hline Strain & $\begin{array}{l}\text { Lag before } \\
\text { growth (h) }\end{array}$ & $\begin{array}{c}\mu^{*} \\
\left(\mathrm{~h}^{-1}\right)\end{array}$ & $\begin{array}{l}t_{\mathrm{d}}^{*} \\
(\mathrm{~h})\end{array}$ & $\begin{array}{l}\text { Maximum penicillin titre } \dagger \\
\text { (units } / \mathrm{ml} \text { ) }\end{array}$ & $\begin{array}{c}\text { Growth yield } \\
\text { (mg dry biomass/mg lysine) }\end{array}$ \\
\hline WIS 54-I 255 & 20 & 0.16 & $4 \cdot 3$ & 120 & - \\
\hline $\mathrm{H}$ & 28 & 0.076 & $9 \cdot c$ & 69 & 39 \\
\hline I $3 a$ & 31 & 0.12 & $5 \cdot 7$ & $1 \cdot 6$ & 38 \\
\hline 45 & 52 & 0.077 & $9 \cdot 0$ & 0.5 & 20 \\
\hline
\end{tabular}

Laboratories, Detroit, Michigan, U.S.A.). Before the assay, penicillin was removed from the sample by penicillinase; sufficient enzyme was added to remove 2000 units penicillin $G$ after $6 \mathrm{~h}$ at $22^{\circ} \mathrm{C}$. The method was capable of estimating lysine concentration down to $3 \mu \mathrm{g} / \mathrm{ml}$. Penicillin was assayed by a cup method with Bacillus subtilis as the assay organism and sodium benzyl penicillin as the standard.

\section{RESULTS}

\section{Characterization of lysine auxotrophs}

Auxanography. Five lysine auxotrophs were isolated, four of which resulted from u.v. treatment, and one from NTG treatment (Table I). None of the strains (designated H, I $3 \mathrm{a}$, 45,27 , and 25) were able to grow on MMI unless it was supplemented with lysine. Of the five isolates, only strains 27 and 25 grew on MMI $+\alpha$-aminoadipate indicating that these were blocked before $\alpha$-aminoadipate, and the remaining strains, H, I 3 a and 45, were blocked after $\alpha$-aminoadipate. No growth was found on MMI + ketoadipate or on MMI + saccharopine. Since strains 27 and 25 grew on $\alpha$-aminoadipate, but not on saccharopine, it is likely that the saccharopine was unable to enter the cell. In view of the fact that strains 27 and 25 were blocked before $\alpha$-aminoadipate, they were not used in subsequent work.

Growth characteristics. The three lysine auxotrophs blocked after $\alpha$-aminoadipate were characterized for growth yield, specific growth rate and maximum penicillin yield (Table 2). They were found to vary considerably from each other and from the parent strain. Strains $\mathbf{H}$ and $\mathrm{r}_{3}$ a were similar in their growth yields on lysine but strain 45 required twice as much lysine for an equivalent amount of growth. Strain WIS 54-I 255 produced the highest titre $(\mathrm{I} 20 \mathrm{u} / \mathrm{ml})$, strain $\mathrm{H}$ produced just over half of this amount, $(69 \mathrm{u} / \mathrm{ml})$, and strains $\mathrm{I} 3 \mathrm{a}$ and 45 produced very low titres of $\mathrm{I} \cdot 6$ and $0.5 \mathrm{u} / \mathrm{ml}$ respectively. 


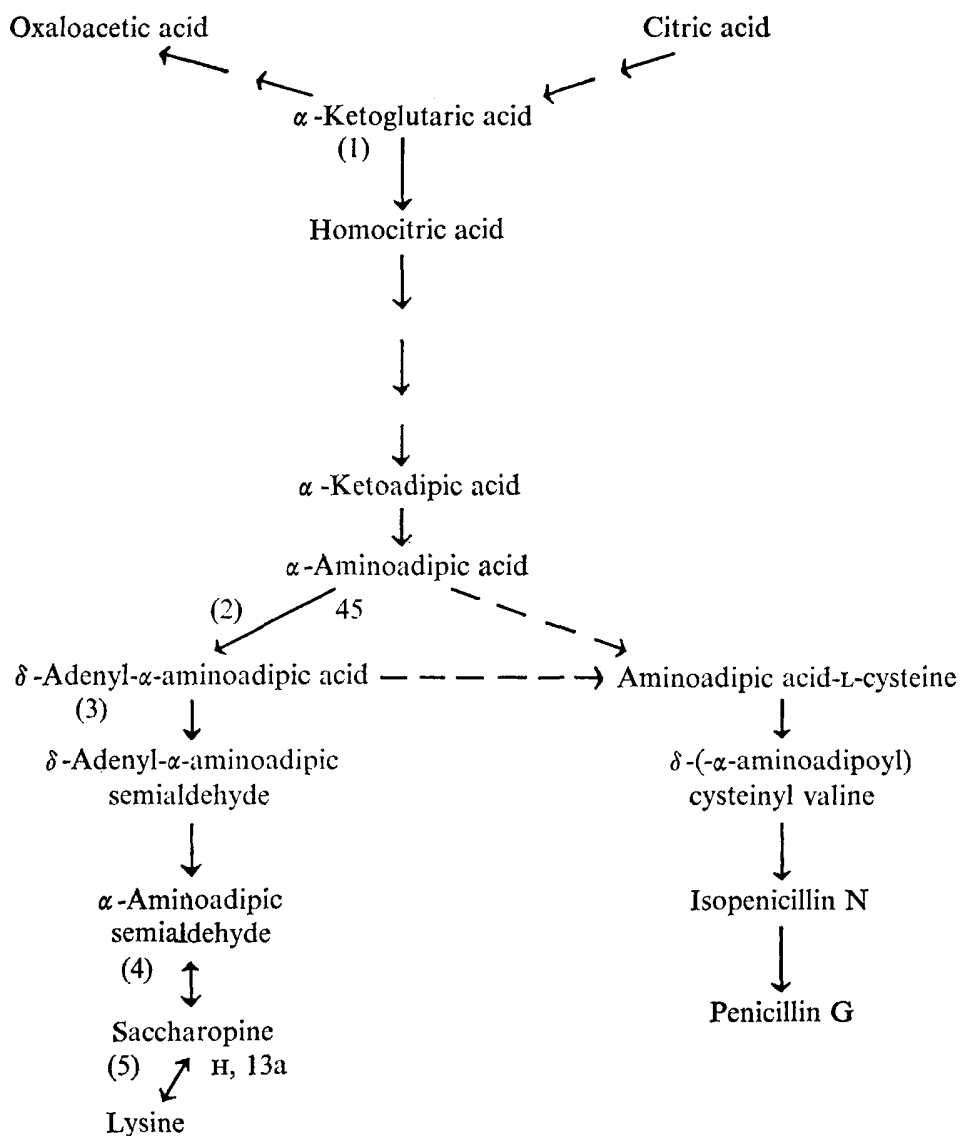

Fig. I. Pathways of lysine and penicillin biosynthesis in Penicillium chrysogenum. (I), Homocitrate synthase; (2), $\alpha$-aminoadipic acid reductase (activated); (3), $\alpha$-aminoadipic acid reductase (reduction); (4), saccharopine reductase; and (5), saccharopine dehydrogenase. Strain 45 is thought to be blocked at position (2) and strains $\mathrm{H}$ and $\mathrm{r} 3 \mathrm{a}$ at position (5). The broken lines indicate two possible branch points.

Biochemical characterization. Three enzymes of the lysine pathway (Fig. I) were assayed: these were $\alpha$-aminoadipic acid reductase (an enzyme system) which converts $\alpha$-aminoadipate to $\alpha$-aminoadipic semialdehyde; saccharopine reductase, which converts saccharopine to $\alpha$-aminoadipic semialdehyde; and saccharopine dehydrogenase, which converts lysine to saccharopine (Fig. I). Their specific activities are shown in Table 3.

Strain 45 showed no $\alpha$-aminoadipic acid reductase activity, but this enzyme was present in the other three strains. The specific activity in strain $\mathrm{H}$ was over ten times that in the parent strain, and that in strain I 3 a almost fifty times greater. The enzymes saccharopine reductase and saccharopine dehydrogenase were active in the parent strain and in strain 45 , but strains $\mathrm{H}$ and $\mathrm{r}$ 3a showed very low activities, although they were about twice as high for saccharopine reductase as for saccharopine dehydrogenase. This indicated that strains $\mathrm{H}$ and I $3 \mathrm{a}$ were blocked between saccharopine and lysine, and that there was also impairment of enzyme activity between $\alpha$-aminoadipic semialdehyde and saccharopine.

Extracts of the four strains were spotted on to thin-layer silica gel chromatograms along with standards of $\alpha$-aminoadipate, saccharopine and lysine. All the strains possessed a 


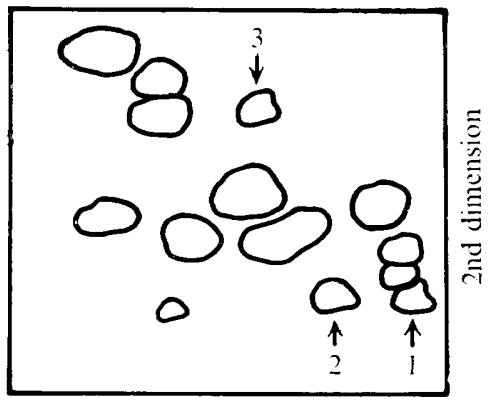

1st dimension

Fig. 2. Two-dimensionsional chromatogram of amino acids extracted from Penicillium chrysogenum strain I 3a. I, Saccharopine; 2, lysine; 3, unknown compound.

Table 3. The activities of $\alpha$-aminoadipic acid reductase, saccharopine reductase and saccharopine dehydrogenase in Penicillium chrysogenum strains wis 54-1 255, $\mathrm{H} \mathrm{I} 3 \mathrm{a}$ and 45

\begin{tabular}{lccc} 
Strain & \multicolumn{3}{c}{ Specific activities } \\
WIS 54-1255 & $\begin{array}{c}\alpha \text {-Aminoadipic } \\
\text { acid reductase* }\end{array}$ & $\begin{array}{c}\text { Saccharopine } \\
\text { reductase }\end{array}$ & $\begin{array}{c}\text { Saccharopine } \\
\text { dehydrogenase }\end{array}$ \\
H & 0.08 & 0.44 & 10.0 \\
I3a & $\mathrm{I} \cdot 0$ & $0.04 \mathrm{I}$ & 0.027 \\
45 & 3.84 & 0.085 & 0.033 \\
45 & 0 & 1.00 & 12.0
\end{tabular}

* Expressed as a decrease in absorbance at $460 \mathrm{~nm}$ measured after $3 \mathrm{~h} / \mathrm{mg}$ of protein.

$\dagger$ Expressed as $100 \times$ micromoles of nicotinamide adenine dinucleotide phosphate reduced $/ \mathrm{min} / \mathrm{mg}$ of protein.

$\ddagger$ Expressed as $100 \times$ micromoles of reduced nicotinamide adenine dinucleotide oxidized $/ \mathrm{min} / \mathrm{mg}$ of protein.

normal complement of amino acids (Fig. 2) and lysine was present in the amino-acid pool of each strain. WIS 54-I255 did not contain $\alpha$-aminoadipic acid (in common with the other three strains) or saccharopine in sufficient quantities to be detected chromatographically. Strains $\mathrm{H}$ and $\mathrm{I} 3 \mathrm{a}$ both possessed a pool of saccharopine. Strain 45 did not accumulate saccharopine but did have an unknown compound that was also found in strain r za but not in strains $\mathrm{H}$ or the parent strain. It was not established what this compound was.

The effect of lysine on penicillin production by Penicillium chrysogenum; strains WIS 54-I255 and $\mathrm{H}$ when grown in a chemostat

Penicillium chrysogenum strain WIS 54-1255 was grown in a chemostat with glucose as the growth-limiting substrate. The concentration of lysine in the medium supplied was varied from o to $400 \mathrm{mg} / \mathrm{l}$. Lysine was estimated microbiologically at each steady state and it was found to be absent regardless of the amount fed in. With no lysine feed, a $q_{\text {pen }}$ of $2.94 \mathrm{u} / \mathrm{mg}$ dry biomass/h was achieved and this fell to $2.5 \mathrm{u} / \mathrm{mg}$ dry biomass/h with a lysine feed concentration of $95 \mathrm{mg} / \mathrm{l}$. The $q_{\text {pen }}$ then dropped almost exponentially as the lysine feed concentration increased (Fig. 3).

Strain $\mathrm{H}$, when grown in the chemostat did not adapt readily to growth and took on average twice as long as the parent strain to reach substrate-limited growth. Reversion took place after approximately $200 \mathrm{~h}$ of substrate-limited growth and therefore only two steady states 


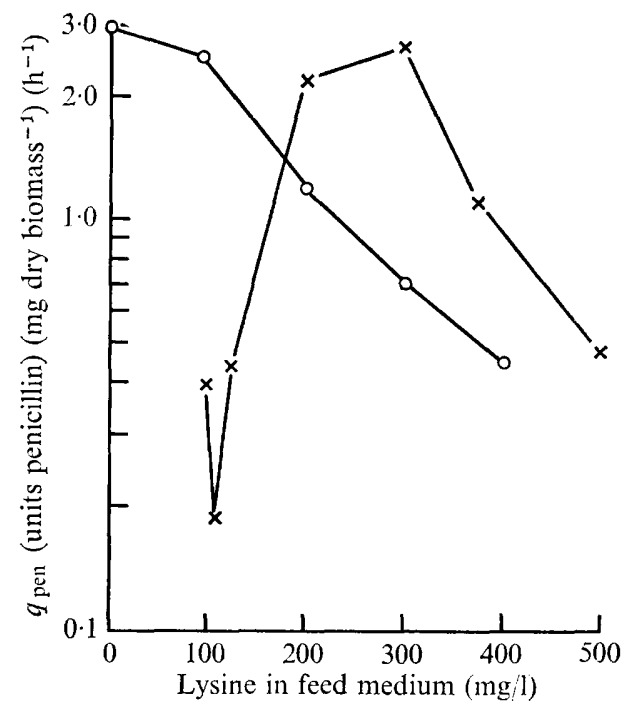

Fig. 3. Semilogarithmic plot of the relationship between specific penicillin production rate $\left(q_{\text {ren }}\right)$ and lysine in the feed medium $(\mathrm{mg} / \mathrm{l})$ for Penicillium chrysogenum, when grown in a glucose-limited chemostat. $O$, Strain WIS 54-1255; $\times$, strain $\mathrm{H}$.

Table 4. Simulated second-stage cultures with Penicillium chrysogenum strain wIS 54-1255

Samples $(25 \mathrm{ml})$ of the culture were transferred to shake flasks from the chemostat during glucoselimited steady state when lysine feed was $0 \mathrm{mg} / \mathrm{l}$ and $q_{\mathrm{pen}}$ was $2.94 \mathrm{u} / \mathrm{mg}$ dry biomass $/ \mathrm{h}$. In one set of flasks either the glucose, $\beta$-aminoadipic acid or lysine was added by means of a diffusion capsule. In another set of flasks, the substance was added directly. After $24 \mathrm{~h}$ shaking, the penicillin and biomass concentrations were determined.

\section{Substance added}

None

$\alpha$-Aminoadipic acid $(3.6 \mathrm{mg})$

$\alpha$-Aminoadipic acid $(3.6 \mathrm{mg})$

Lysine ( $1.8 \mathrm{mg}$ )

Lysine ( $1.8 \mathrm{mg}$ )

Glucose (240 mg)

Glucose (240 mg)

$\alpha$-Aminoadipic acid $(3.6 \mathrm{mg})+$ glucose $(240 \mathrm{mg})$

\section{Method of addition}

\begin{tabular}{ll}
\multicolumn{1}{c}{$\quad$} & $0 \cdot 9$ \\
Direct & $\mathrm{I} \cdot 4$ \\
Diffusion & $2 \cdot 2$ \\
Direct & $0 \cdot 46$ \\
Diffusion & $\mathrm{I} \cdot 2$ \\
Direct & $\mathrm{I} \cdot 2$ \\
Diffusion & $3 \cdot 2$ \\
Direct & $2 \cdot \mathrm{I}$
\end{tabular}

per run were achieved. The concentration of lysine was varied from about fivefold excess down to the limiting level and at all times, when assayed microbiologically, it was found to be absent from the growth medium. As the lysine concentration in the medium feed increased $q_{\text {pen }}$ rose and the relation shown in Fig. 3 was obtained. The maximum $q_{\text {pen }}$ was achieved when lysine was $180 \%$ in theoretical excess (calculated from the dry biomass and the growth yield for lysine). Thus for the maximum penicillin production the mutant required a theoretical lysine excess of about $\mathrm{I} 80 \%$, whereas the parent strain required no lysine at all.

Simulated second-stage penicillin production. Experiments were set up to measure penicillin production by mycelium taken from steady-state chemostat cultures. The results gave further information about the response of cultures to various additives, also the cultures simulated the conditions which would occur in a second-stage chemostat run in series with the first. The results are given in Table 4 and 5 . In all cases the $q_{\text {pen }}$ fell in the 


\section{Table 5. Simulated second-stage cultures with Penicillium chrysogenum strain $\mathrm{H}$}

Samples $(25 \mathrm{ml})$ were transferred to shake flasks from the chemostat during a glucose-limited steady state when lysine was $96.4 \%$ in theoretical excess and $q_{\text {pen }}$ was $2.2 \mathrm{u} / \mathrm{mg}$ dry biomass $/ \mathrm{h}$. In one set of flasks, either the glucose, $\alpha$-aminoadipic acid or lysine was added by means of a diffusion capsule. In another set of flasks the substance was added directly. After $24 \mathrm{~h}$ the penicillin and biomass concentrations were determined.

Substance added

None

$\alpha$-Aminoadipic acid $(3.6 \mathrm{mg})$

$\alpha$-Aminoadipic acid $(3.6 \mathrm{mg})$

Lysine $(\mathrm{I} \cdot 8 \mathrm{mg})$

Lysine ( $1 \cdot 8 \mathrm{mg})$

Glucose (240 mg)

Glucose (240 mg)

$\begin{array}{lc}\begin{array}{c}\text { Method of } \\ \text { addition }\end{array} & \begin{array}{c}q_{\text {pen }} \\ \text { (units/mg dry biomass/h) }\end{array} \\ \text { Direct } & 0.76 \\ \text { Diffusion } & \mathrm{I} \cdot 3 \\ \text { Direct } & \mathrm{I} \cdot 55 \\ \text { Diffusion } & 0.68 \\ \text { Direct } & 0.5 \\ \text { Diffusion } & 0.8 \\ & \mathrm{I} \cdot 8\end{array}$

second stage except when glucose was added by diffusion. Direct addition of excess glucose inhibited penicillin synthesis. Compared with no addition, $\alpha$-aminoadipic acid, particularly when added by diffusion, stimulated penicillin production. Lysine, when added directly, inhibited penicillin production, but stimulated slightly when added by diffusion.

It was also found that $\alpha$-aminoadipic acid when directly added, partially overcame the inhibition of penicillin synthesis by excess glucose.

\section{DISCUSSION}

The blocks in the metabolic pathway to lysine in three lysine auxotrophs of Penicillium chrysogenum (strains $45, \mathrm{I} 3 \mathrm{a}$ and $\mathrm{H}$ ) have been narrowly identified by enzyme assays and chromatography of amino acid pools. Either of these blocks in the lysine pathway caused a large decrease in penicillin synthesis which could be overcome only in strain $\mathrm{H}$ by an optimum feed of lysine.

Somersen, Demain \& Nunheimer (I96I) showed, on the basis of final penicillin titre, that in a suspension of resting mycelium with lactose and precursor, $\alpha$-aminoadipic acid stimulates penicillin production. Our studies on simulated second-stage cultures show how $\alpha$-aminoadipic acid stimulates the specific penicillin production rate $\left(q_{\mathrm{pen}}\right)$ and indicate that a slow feeding of $\alpha$-aminoadipic acid can be more effective than addition in one dose. This would accord with the observation of Somersen et al. that an excess of $\alpha$-aminoadipic acid could inhibit penicillin production.

It was envisaged at the initiation of this work that the penicillin titre of Penicillium chrysogenum could be increased approximately threefold by feeding lysine at a low concentration to lysine auxotrophs blocked after $\alpha$-aminoadipate. However, with the mutants obtained here the maximum titre obtained was slightly less than that of the parent strain. Surprisingly, mutant strain $\mathrm{H}$, grown in a chemostat with glucose as the growth-limiting substrate, required a lysine feed considerably in excess of the maximum for growth requirements in order to achieve the maximum penicillin titre. The organism used all the lysine supplied, at least up to five times the growth requirement. Hunter \& Segal (I97I) also found that lysine was readily taken up by $P$. chrysogenum, its uptake being constitutive and independent of concurrent protein synthesis. Since lysine can be easily taken up, it must therefore be readily utilized. However, its catabolism in fungi has not been elucidated, although two pathways have been postulated. 
The transformation of lysine to pipecolic acid was demonstrated in Neurospora crassa by Schweet, Holden \& Lowy (1954), but the intermediate compounds were not identified. Hunter \& Segel (I97I) tentatively identified the first breakdown product of lysine in Penicillinium chrysogenum as $\alpha$-keto- $\epsilon$-aminocaproate and thus the pathway could proceed via $\alpha$-keto- $\epsilon$-aminocaproate to pipecolic acid and then via $\alpha$-aminoadipic semialdehyde, $\alpha$-aminoadipic acid and $\alpha$-keto-adipic acid to glutaric acid.

However, Rothstein (I965) identified in Hansenula saturnus $\epsilon$ - $N$ acetyllysine, $\epsilon$-acetamido$\alpha$-hydroxycaproic acid and $\epsilon$-amino- $\alpha$-hydroxycaproic acid as breakdown products of lysine and suggested that acylation would prevent cyclization of lysine into the pipecolic acid- $\alpha$ aminoadipic acid pathway and it would proceed instead via acetyllysine, $\epsilon$-acetamido- $\alpha$ hydroxycaproate to glutaric acid. The compound $\epsilon$-acetamido- $\alpha$-hydroxycaproate was also recognized in Neurospora crassa by Schweet et al. (1954) and it may be possible that the acylated and $\alpha$-aminoadipate pathways exist in the same organism. There have also been other compounds such as $\delta$-amino valerate identified from breakdown of lysine in Torulopsis utilis (Sagisaka \& Shimura, I96I) and carnitine identified after breakdown of labelled lysine in $N$. crassa (Horne, Tanphaichitr \& Broquist, I97I).

It cannot therefore be said with any certainty which pathway is followed but the unexpected stimulation of penicillin production by lysine in Penicillium chrysogenum strain $\mathrm{H}$ could be attributed to the breakdown of lysine via $\alpha$-aminoadipate thus making the latter compound available for penicillin production. This theory, however, does not explain why, in the parent strain, a maximum $q_{\mathrm{pen}}$ was reached at zero lysine feed concentration and why in the mutant strain $\mathrm{H}, q_{\text {pen }}$ declined at a rate similar to that of the parent strain after a $180 \%$ theoretical lysine excess was reached. The decline of $q_{\text {pen }}$ in the parent strain could be due to lysine or some breakdown product of lysine inhibiting or repressing the first enzyme of the pathway, homocitrate synthase. However, this feedback control did not become apparent in the mutant strain until a $q_{\mathrm{pen}}$ near to the maximum $q_{\mathrm{pen}}$ achieved with the parent strain was attained. There was evidence from the simulated second-stage experiments that $\alpha$-aminoadipate could have been limiting penicillin production.

The reason for the stimulation of penicillin production by lysine in Penicillium chrysogenum strain $\mathbf{H}$ remains unexplained and it would be necessary to conduct similar experiments using other lysine requiring mutants blocked after $\alpha$-aminoadipate to see if similar stimulation occurs. However, the continuous cultivation of auxotrophs presents one great difficulty, that of reversion. The lysine and penicillin biosynthetic pathways also need further elucidation to see whether lysine is the regulatory compound or whether some breakdown product of lysine or indeed other compounds of the pathways may be controlling factors. It is also desirable to establish by which route lysine is catabolized.

The prospects, therefore, of increasing penicillin yield by genetic manipulation of Jysine metabolism may be realized when a further elucidation of the metabolic pathways involving lysine and penicillin is at hand.

A. L. Demain (personal communication) has suggested that the branch point between the lysine and penicillin pathways is adenyl $\alpha$-aminoadipic acid rather than $\alpha$-aminoadipic acid; this could explain the virtual complete failure of strain 45 to produce penicillin if the block at the $\alpha$-aminoadipic acid reductase occurred at the adenylation step.

The maximum $q_{\mathrm{pez}}$ value obtained in this work with strain wIS 54-I 255 was $3 \cdot 2 \mathrm{u} / \mathrm{mg}$ dry mycelium/h (compared with $\mathrm{I} \cdot 8$ in the work of Pirt \& Righelato (I967)). This significant difference remains unexplained. There are two possible causes. One is that at the initiation of the present work isolated colonies of the parent strain were screened for maximum penicillin titre and the best one was selected; hence a high producing natural variant may 
have been selected. Another possible cause is that, instead of phenylethylamine acetate a different side-chain precursor, phenylacetic acid, was used by Pirt \& Righelato (1967). It is assumed that benzyl penicillin is produced in either case. Whether different precursors of the benzyl side chain can affect the $q_{\text {pen }}$ has not been investigated, but the question is raised by these results.

We thank Dr H. P. Broquist for kindly supplying us with saccharopine and $\alpha$-ketoadipat e and I.C.I. Ltd for financial support during the course of this work.

\section{REFERENCES}

Adelberg, E. A., Mendel, M. \& Chen, G. C. C. (1965). Optimal conditions for mutagenesis by $N$-methyl$N^{\prime}$-nitro- $N$-nitrosoguanidine in Escherichia coli. Biochemical and Biophysical Research Communications I8, 788-795.

Clutterbuck, A. U. \& Sinha, R. H. (I966). Effect of $N$-methyl- $N^{\prime}$-nitro- $N$-nitrosoguanidine on Aspergillus nidulans. Aspergillus Newsletter $7,12-13$.

Demain, A. L. (1957). Inhibition of penicillin formation by lysine. Archives of Biochemistry and Biophysics 67, 244-246.

Demain, A. L. (1966). Industrial fermentations and their relation to regulatory mechanisms. Advances in Applied Microbiology 8, $\mathrm{I}-27$.

FueLlstedt, T. A. \& OGUR, M. (1970). Effects of supersuppressor genes on enzymes controlling lysine biosynthesis in Saccharomyces. Journal of Bacteriology 101, 108-I I7.

Horne, D. W., Tanphaichitr, V. \& Broquist, H. P. (197I). Role of lysine in carnitine biosynthesis in Neurospora crassa. Journal of Biological Chemistry 246, 4373-4375.

Huggett, A. St. G. \& Nixon, D. A. (1957). Enzymatic determination of blood glucose. Biochemical Journal 66, I 2p.

Hunter, D. R. \& Segel, I. H. (1971). Acidic and basic amino acid transport systems of Penicillium chrysogenum. Archives of Biochemistry and Biophysics 144, 168-183.

JARVIS, F. G. \& JoHnson, M. J. (1947). The role of the constituents of synthetic media for penicillin production. Journal of the American Chemical Society 69, 3010-3017.

JoNes, E. E. \& Broquist, H. P. (I 966). Saccharopine, and intermediate of the $\alpha$-aminoadipic acid pathway of lysine biosynthesis. III. $\alpha$-Aminoadipic semialdehyde glutamate reductase. Journal of Biological Chemistry 24r, 3430-3434.

Lowry, O. H., Rosebrough, N. J., Farr, A. L. \& Randall, R. J. (195I). Protein measurement with the Folin phenol reagent. Journal of Biological Chemistry 193, 265-275.

Maragoudakis, M. E., Holmes, H. \& Strassman, M. (1967). Control of lysine biosynthesis in yeast by a feedback mechanism. Journal of Bacteriology 93, I677-1680.

Moyer, A. J. \& CoghiLl, R. D. (I946). Penicillin. VIII. Production of penicillin in surface culture. Journal of Bacteriology 51, 57-78.

PIRT, S. J. (I969). Microbial growth and product formation. Symposium of the Society for General Microbiology 19, 199-221.

PIRT, S. J. (1971). The diffusion capsule, a novel device for the addition of a solute at a constant rate to a liquid medium. Biochemical Journal 121, 293-297.

Pirt, S. J. \& Callow, D. S. (1960). Studies of the growth of Penicillium chrysogenum in continuous-flow culture with reference to penicillin production. Journal of Applied Bacteriology 23, 87-98.

Pirt, S. J. \& Righelato, R. C. (I967). Effect of growth rate on the synthesis of penicillin by Penicillium chrysogenum in batch and chemostat cultures. Applied Microbiology 15, I 284-I 290.

Pontecorvo, G., Roper, J. A., Hemmons, L. M., MacDonald, K. D. \& Bufton, A. L. (I953). Genetics of Aspergillus nidulans. Advances in Genetics 5, $14 \mathrm{I}-438$.

Rothstein, M. (1965). Intermediates of lysine dissimilation in yeast Hansenula saturnus. Archives of Biochemistry and Biophysics III, 467-476.

Sagisaka, S. \& Shimura, K. (1959). Enzymatic reduction of $\alpha$-aminoadipic acid by yeast enzyme. Nature, London, 184, I 709-1710.

SAgisaka, S. \& ShimURA, K. (I96I). Lysine biosynthesis. II. Metabolic fate of D-L- $\alpha$-aminoadipic acid-6- ${ }^{14} \mathrm{C}$ in T. utilis. Journal of Biochemistry 49, 392-396. 
Schweet, R. S., Holden, J. J. \& Lowy, P. H. (1954). Metabolism of lysine in Neurospora. Journal of Biological Chemistry 2II, 5I 7-529.

Somersen, N. L., Demain, A. C. \& Nunheimer, T. D. (I96I). Reversal of lysine inhibition of penicillin production by $\alpha$-aminoadipic acid or adipic acid. Archives of Biochemistry and Biophysics 93, 238-24I.

TuCCI, A. F. (1969). Feedback inhibition of lysine biosynthesis in yeast. Journal of Bacteriology 99, 624-625.

WRIGHT, D. G. \& CALAM, C. T. (I968). Importance of the introductory phase in penicillin production using continuous flow culture. Chemistry and Industry I 274-I 275. 